\title{
THE MORPHOLOGY-PHONOLOGY INTERFACE: ISOLATING TO POLYSYNTHETIC LANGUAGES*
}

\author{
IRENE VOGEL \\ Linguistics Department \\ University of Delaware \\ Newark, DE 19716 \\ USA \\ ivogel@udel.edu
}

\begin{abstract}
Given the substantial variation in the nature of the grammatical word (GW) across languages, this paper addresses the question of whether the Phonological Word (PW) exhibits the same degree of variation or rather abstracts away from it due to the typically flatter nature of the phonological hierarchy. Various types of languages are examined, focusing on isolating and polysynthetic languages - opposite ends of a word structure continuum. It is demonstrated that, indeed, the PW exhibits substantially less variation across languages than might be expected on the basis of the differences in GW structure. Furthermore, it is shown that an additional constituent (i.e., the Clitic Group, renamed Composite Group) is required between the PW and the Phonological Phrase to fully account for the interface between morpho-syntactic and phonological structures.
\end{abstract}

Keywords: Prosodic Phonology, phonological word, clitic group, isolating languages, polysynthetic languages

\section{Introduction}

It is widely accepted that the phonological constituents above the level of the foot are constructed via a mapping procedure from morphological and syntactic structure onto a hierarchical phonological structure (cf. Selkirk 1972; 1980; 1986; Nespor-Vogel 1982; 1986; Booij 1983, among others). The present paper addresses the interface between morphology

* I would like to thank the participants at the 12th Annual Morphology Meeting for their helpful comments and suggestions. 
and phonology, and focuses on the relationship between the morphological structures of words and the phonological structures onto which they are mapped.

In the hierarchical phonological structure, at least one phonological constituent is recognized between the foot and the Phonological Phrase, and it is here that we can best observe the manifestation of the morphology-phonology interface. As Hall (1999b, 2) points out, "since this constituent can be shown to be roughly the size of a grammatical word, ${ }^{1}$ it is often referred to in the literature as the "phonological word', or alternatively as the 'prosodic word'." It is precisely the view that the constituent in question, referred to here as the PW, is roughly co-extensive with the grammatical or morphological word that forms the basis of the present investigation.

Given that there is substantial variation in the nature of the grammatical word (GW) across languages, the question that arises is whether the Phonological Word constituent reflects the same degree of variation or rather abstracts away from it, at least to some extent, resulting in more similar phonological than morphological structures. Specifically, we must ask whether the PW in typically isolating languages such as Vietnamese and Chinese, where the GW often consists of a single morpheme, is significantly different from typically polysynthetic languages such as Dakota and Cree, where the GW frequently corresponds to an entire sentence in English. If the PW is roughly the same size as the GW, we would expect particularly small PWs in the former type of language, but particularly large ones in the latter type.

In order to investigate this question, the present paper examines different types of languages, focusing on isolating and polysynthetic languages, which represent the opposite ends of a continuum of word types in terms of their length and complexity. On the basis of specific phonological considerations, a general definition of the $\mathrm{PW}$ is proposed, and it is demonstrated that the PW, thus defined, exhibits substantially less variation across languages than might be expected on the basis of the differences in GW structure. It is also suggested that an additional constituent (i.e., the Clitic Group) is required between the PW and the Phonological Phrase to fully account for the interface between morphosyntactic and phonological structures.

In the following sections, a standard word structure typology is first briefly presented, focusing on the ends of the continuum: isolating and

${ }^{1}$ The emphasis is mine.

Acta Linguistica Hungarica 55, 2008 
polysynthetic languages. The phonological phenomena that are generally used in identification of the PW are then reviewed. A general definition of the PW is proposed, and a number of implications of this definition are examined. In subsequent sections, it is shown how the definition applies to isolating and polysynthetic languages as well as to other types. Finally, general conclusions are drawn to the effect that the degree of variability in Grammatical Word structures is substantially reduced in the corresponding Phonological Word structures, in accordance with the widely observed lack of isomorphism between morphological (and syntactic) structure and phonological structure.

\section{Morphological typology}

A traditional way of classifying languages on the basis of their word structure ranges from isolating languages at one extreme to polysynthetic languages at the other (e.g., Comrie 1981, 39-49). While such a typology may have certain theoretical drawbacks, it nevertheless allows us to distinguish languages on the basis of the relative size of typical (grammatical) words in terms of the number and nature of the morphemes included in these words. As will be seen, these are precisely the properties that are relevant for the interface with phonology.

In general terms, an isolating language is "[...] ideally, a language where there is one-to-one correspondence between words and morphemes" (ibid., 39). Typical examples of isolating languages are Chinese and Vietnamese. While not all GWs in such languages are monomorphemic, this is the general tendency, as illustrated in (1).

(1) Isolating language: Vietnamese (ibid., 40)

Khi tôi đến nhà bạn tôi, chúng, tôi bắt dầu làm bài.

when I come house friend I pl I begin do lesson

'When I came to my friend's house, we began to do lessons.'

By contrast, polysynthetic languages generally "[...] combine a large number of morphemes, be they lexical or grammatical, into a single word, often corresponding to a whole sentence in English [...]" (ibid., 42). Typically, native American languages are polysynthetic languages. ${ }^{2}$ While

${ }^{2}$ Many native American languages are also categorized as "incorporating", and exhibit particularly long GWs, often corresponding to sentences in English. While 
monomorphemic words exist in such languages, the general tendency is for (grammatical) words to be relatively long, as illustrated in (2).

(2) Polysynthetic language: Moses-Columbia Salish (Czaykowska-Higgins 1998, 167)

$/ \mathrm{k}^{\prime \mathrm{w}} \lambda^{\prime}-\mathrm{k}^{\prime \mathrm{w}} \lambda^{\prime \prime} \quad-\mathrm{p}=$ ákst $-\min -\mathrm{t}-\emptyset-\mathrm{s} /=\left[\mathrm{k}^{\prime}{ }^{\mathrm{w}} \lambda^{\prime}{ }^{\prime}{ }^{\prime \mathrm{w}}{ }^{\prime}{ }^{\prime} p a ́ k s t m s\right]$ redup separate inch hand rel $\operatorname{tr} 303 \mathrm{~s}^{3}$

'He dropped it.'

Although the focus of this paper is these two extreme types of word structures, it should be noted that relatively long GWs may also arise in agglutinating languages such as Turkish and Hungarian, although monomorphemic words are not excluded, as illustrated in (3). The so-called fusional languages, typical of the Indo-European family, tend to have GWs of an intermediate length, although here, too, we may also find very short, monomorphemic words, as shown in (4). By comparison, templatic languages, typical of the Semitic family, tend to have relatively short, but not monomorphemic, GWs since most of the morphology is applied in relation to the structure determined by the root consonants; affixes are added relatively infrequently to create longer strings (e.g., (5)).

(3) Agglutinating language: Turkish (Kabak-Vogel 2001)
(a) çocuk
'child'
(b) çocuk - lar - im - ì - in 'of our children'
child pl pe1 pl of

(4) Fusional language: Italian
(a) caffè
'coffee'
(b) special - izz - ass - imo '(if we) specialized'

special - ize past subj $1 \mathrm{pl}$

such a distinction may be problematic from the morpho-syntactic perspective, both language types involve the same issues with regard to their interface with phonology.

3 The symbol $/ \lambda " /$ is used here to represent a glottalized lateral affricate, in place of the lambda with a slash followed by a single apostrophe used in the source. Furthermore, 'redup', 'inch', 'rel', 'tr', ' 30 ' and ' $3 \mathrm{~s}$ ' refer, respectively, to reduplicant, inchoative, relational, transitive, third person object and third person subject morphemes.

4 There may be other slightly different ways of analyzing the morphological structure of this word (e.g., breaking down - ass into a theme vowel $a$ of the first conjugation followed by a past subjunctive morpheme). While such forms may 
(5) Templatic language: Arabic

/šahad-aat/ 'certificate-s'

In each of these additional language types, compounding is also possible and may indeed account for somewhat longer strings of morphemes, but they still tend to be substantially shorter and less complex than the sentence-like words of polysynthetic languages.

Given the systematic diversity in word structures across languages, the question we must now address is to what extent this diversity is reflected in the phonological structure. That is, while there are fundamental differences in the nature of (grammatical) word formation, it remains to be seen whether or not the interface between these structures and those of the corresponding phonological constituents exhibits a related systematic diversity. Put very simply, the question we must address is the following: are there fundamental differences in the Phonological Words of Vietnamese and Salish?

\section{Identification of the Phonological Word}

The Phonological Word is the most widely accepted constituent in the phonological/prosodic hierarchy between the purely phonological syllable and foot structures on the one hand, and the structures that involve the interface with syntax, Phonological Phrases (PPh) (cf., among others, Dixon-Aikhenvald 2002), as shown in (6).

(6) Location of Phonological Word

Phonological Phrase

|

Phonological Word

Syllable/Foot

In some analyses it is argued that there is need for an additional phonological constituent structure between the syllable/foot and the PPh. The Prosodic Stem is one such constituent that has been proposed for Bantu languages. It is argued that this additional constituent is situated in the

be somewhat controversial in terms of their morphological structure, the crucial point here is that the entire GW is intermediate in length between those typically found in isolating languages and polysynthetic languages. 
phonological hierarchy below the level of the PW (cf. Downing 1999). By contrast, it has also been argued that an additional constituent is needed between the $\mathrm{PW}$ and the $\mathrm{PPh}$, originally referred to as the Clitic Group (CG) (e.g., Hayes 1989; Nespor-Vogel 1986). In more recent work, some of the early objections to the structure of the CG have been resolved, and this constituent has continued to play a role in several analyses (e.g., Vogel 1999, for Italian; Kabak-Vogel 2001, for Turkish). While not the focus of the present investigation, the issue of an additional phonological constituent involved in the mapping of morphological to phonological structure will be addressed briefly below.

In order to evaluate the potential similarities and/or differences between the PWs in different types of languages, we must first consider the criteria that are used in establishing the domain of the PW.

\subsection{The simplest equation: $P W=G W$}

The simplest relationship between Phonological Words and the corresponding Grammatical Words would be a one-to-one correspondence. Taking the two ends of the continuum mentioned above, this would mean that we should find many short PWs in a language such as Vietnamese, as illustrated in (7). By contrast, we should find one long PW in a language such as (Moses-Columbia) Salish, as in (8). These examples represent the equation $\mathrm{PW}=\mathrm{GW}$, although this is not necessarily the result that will be proposed below.

As will be seen below, the simple equation $\mathrm{PW}=\mathrm{GW}$ does not accurately account for either isolating or polysynthetic languages. Indeed, it is inadequate for other types of languages (i.e., agglutinating, fusional, templatic) as well.

(7) Vietnamese PWs $(\mathrm{PW}=\mathrm{GW})$

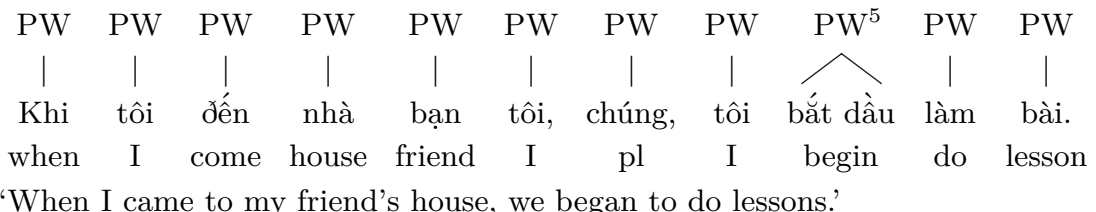

'When I came to my friend's house, we began to do lessons.'

5 The word for 'begin' contains two morphemes and would be considered a compound. Since a compound would be considered a single GW, in the present, simplified structure (i.e., $\mathrm{PW}=\mathrm{GW}$ ) such an item would also be considered a single PW. 
(8) Moses-Columbia Salish $(\mathrm{PW}=\mathrm{GW})$

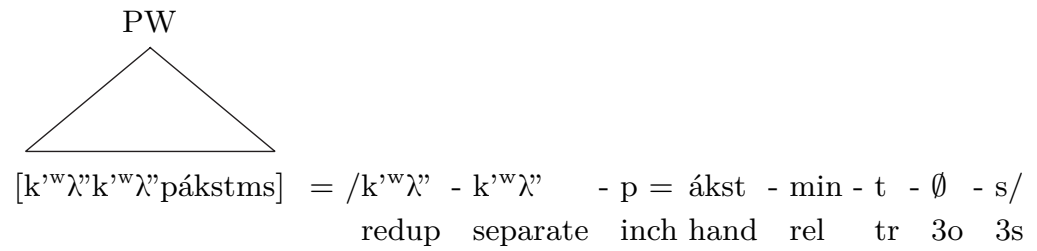

'He dropped it.'

As will be seen below, the simple equation $\mathrm{PW}=\mathrm{GW}$ does not accurately account for either isolating or polysynthetic languages. Indeed, it is inadequate for other types of languages (i.e., agglutinating, fusional, templatic) as well.

\subsection{Criteria for identifying the $P W$}

Typically, the types of morphemes that are candidates for inclusion within a PW are roots, derivational affixes, inflectional affixes, clitics, and function words. Questions arise, however, with regard to which of these items must be included in a given $\mathrm{PW}$, and on what grounds this determination is made. In general, three types of phonological properties are taken as criteria in establishing the PW constituent. That is, the PW is considered to be the domain of (a) phonological rules, including stress assignment, (b) phonotactic constraints, and (c) minimality constraints (cf. among others, Hall 1999a;b; Vogel 2006).

It has been argued, for example, that the $\mathrm{PW}$ is the domain of the rule of (intervocalic) /s/-Voicing in northern Italian (e.g., NesporVogel 1986; Vogel 2006). This rule results in the presence of [z] in words such as $i[\mathrm{z}]$ ola 'island' and po[z]-are '(to) pose', morpheme-internally and before the infinitive morpheme, -are, respectively. By contrast, we do not observe voicing with clitics and across the members of a compound, as in guardando-[s] $i$ 'looking at oneself' and porta-[s] apone 'soap dish'.

With regard to phonotactics, it has been shown that in Dutch, the $\mathrm{PW}$ is the domain of the phonotactic constraint which prohibits sequences in which schwa is preceded and followed by the same consonant other than $/ \mathrm{s} /$ or $/ \mathrm{n} /$. Thus, eik[ə]l 'acorn' is permitted, but $* e i k[$ ə] $] k$ is not. The

${ }^{6}$ Note that the hyphens are only used to draw attention to the various morpheme junctures here; they do not have any orthographical or theoretical status. 
constraint is not, however, in effect across the members of a compound (e.g., vestibul[ə] lamp 'hall lamp') (Booij 1999, 57).

The criterion of prosodic minimality is less consistent in signaling the PW. According to Dixon 1980, many Australian languages require a word to consist of at least two syllables, and similar types of restrictions have also been proposed for other languages including Dutch, SiSwati and Cree, among others (cf. Hall 1999b, 7). While such a criterion for identifying the PW may be effective in certain languages, it cannot be used for all languages. For example, in French, Italian and Spanish, the word for 'tea' is pronounced as [te], a single open syllable with a short vowel. Since minimality constraints generally require two syllables, or at least two moras, words of this sort would be considered subminimal, despite their prevalence in these and other languages.

In sum, what such considerations reveal is that there are particular phonological properties that distinguish among GW structures. While some GWs, or parts of GWs, might exhibit the properties in question, not all do. This is the case in both the Italian and Dutch compoundswhich, on the one hand, constitute GWs, but on the other hand, fail to exhibit the crucial phonological rule or constraint of the PW. Thus, in all languages there will be specific phonological properties associated with the PW constituent; however, not all three types of properties discussed are crucial in all languages.

\section{Generic PW definition and some implications}

Given, on the one hand, that cross-linguistically we observe similar types of phenomena used in defining the PW, and on the other hand, that the specific properties of these phenomena may vary substantially, the following generic definition is proposed:

(9) Generic definition of PW

A PW consists of a single root plus any additional morphemes within the "grammatical word" such that the resulting constituent exhibits the properties determined to be the crucial PW domain properties for the language in question (i.e., application of P-rules, stress, phonotactic constraints, etc.). ${ }^{7}$

${ }^{7}$ It should be noted that this PW definition is similar in many respects to the PW definition given in Nespor-Vogel (1986), while it is different in others, as will be indicated where relevant. 
This definition is very simple and is intended to apply to all languages regardless of their word structures. In the remainder of this section, a number of crucial implications of this definition are discussed in relation to various types of languages.

\subsection{Implication 1: The smallest $P W$ is a root}

In isolating languages such as Vietnamese, it is not only the case that a high percentage of GWs are PWs, but also that each PW coincides with a single root. As there are few if any derivational and/or inflectional affixes in such languages, in most cases the only material available to constitute the PW is the root itself.

The possibility of isomorphism between roots and PWs is not, however, limited to isolating languages. Rather, any language that permits "free roots" will exhibit PWs that consist of a single root, regardless of the typological category of the language. For example, we find numerous instances of PW = root in English, as well as instances of PWs consisting of a single root in fusional languages such as Italian, agglutinating languages such as Turkish, and even polysynthetic languages such as Lushootseed (cf. Beck 1999), as illustrated below.

(10) $\mathrm{PW}=$ root
a. English:
[potato $]_{\mathrm{PW}}$
b. Italian:
[città $]_{\mathrm{PW}}$ 'city'
c. Turkish:
[çocuk $]_{\mathrm{PW}}$ 'child'
d. Lushootseed:
$\left[\text { stúləlk }^{\mathrm{w}}\right]_{\mathrm{PW}} \quad$ 'river'

Thus, we find PWs consisting of a single root in languages at both ends of the word structure typology, as well as in between. The difference between isolating languages and the other languages is therefore not in the fundamental structure of such PWs, but rather in the relative frequency of PWs that coincide with a single root.

While the smallest PW may consist uniquely of a root in certain cases, languages that permit affixation generally include some or all derivational and inflectional affixes associated with a root in the PW with that root. For example, in Italian, all suffixes (and several prefixes) combine with a root to form a single PW (cf. Nespor-Vogel 1986), and in Turkish the same is true for most suffixes (cf. Kabak-Vogel 2001). In English, it is common to find a combination of some suffixes and prefixes, 
essentially those previously analyzed as Level 1 (or "+ boundary") affixes, combined in a PW with the associated root. Such cases are illustrated in (11), where the root is underlined in each example.

(11) $\mathrm{PW}=$ root + affixes
a. Italian: [special - izz - ass - imo $]_{\mathrm{PW}}$
'(if we) specialized'
b. Turkish: [çocuk - lar - im - iz - in $]_{P W}$ 'of our children'

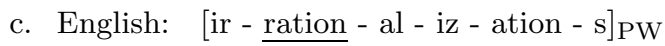

Finally, it should be noted that not all languages exhibit PWs consisting uniquely of a root. In templatic languages such as Arabic and Hebrew, where the roots typically consist of a sequence of consonants, these roots cannot constitute PWs (or GWs for that matter), since they are not "free roots". That is, they may not surface on their own, without the interspersing of the vowels needed to create the desired inflected, and possibly derived, surface form (e.g., [kitaab] 'book', [kutub] 'books', [katab] 'he wrote', etc. from the tri-consonantal root $\{\mathrm{ktb}\}){ }^{8}$ It should be noted that such cases do not violate the generic PW definition since it remains the case in these languages, too, that the PW is not smaller than a root. Furthermore, it is not these roots, but rather the combination of a given root and the related vowels, that constitute the PW that is defined by the usual types of phonological properties (i.e., phonological rules, phonotactic constraints, and minimality constraints).

\subsection{Implication 2: Each root in a compound constitutes a separate $\mathbf{P W}$}

Related to Implication 1 is the second implication that each root will form its own PW. Of course, this is only possible in the strictest sense if the root is a "free root", or at least one that meets the phonological requirements established for the $\mathrm{PW}$ in the language in question. Thus, in isolating languages such as Vietnamese and Chinese, a multi-morpheme GW will typically consist of several roots, and thus contain as many PWs. For example, the single (grammatical) word for "begin" seen above in (7) will now be analyzed as two PWs, as in (12a). Compounds in languages with numerous free roots such as English will also typically have PWs consisting only of each root, as illustrated in (12b).

\footnotetext{
${ }^{8}$ The Arabic examples here and below are drawn from Mitchell (1962).
} 
(12) Compounds: root $=\mathrm{PW}$

(a) Vietnamese

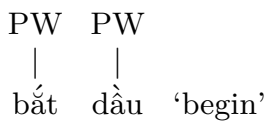

(b) English

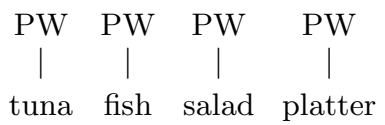

By contrast, "bound roots" generally do not constitute PWs on their own in compounds any more than they would constitute individual lexical items. In fusional languages, most roots are "bound" in that they usually require inflectional suffixes in order to be well-formed GWs, as well as PWs. In Italian, for example, in a compound such as lava piatti 'dish washer', while we can identify the roots as lav- 'wash' and piatt'dish', these roots do not themselves form PWs. Aside from lacking the morpho-syntactically obligatory inflections, with regard to their phonological properties, it can be observed that both words violate Italian phonotactic restrictions that do not permit the consonants in question in word final position.

When an otherwise bound root conforms to the phonotactics of the language, it is possible, at least in some cases, for the root to constitute a PW on its own. For example in English, if the first part of luke warm is considered a bound root, it may nevertheless have the status of PW since it satisfies the necessary phonological requirements. ${ }^{9}$

Finally, in templatic languages such as Arabic, if the roots only consist of consonants, they must be considered bound roots, and it follows that they cannot form PWs on their own. Aside from any meaning they contribute, additional vowels are necessary to enable the formation of

${ }^{9}$ It might be argued that many terms based on Greek roots (e.g., psychology, telegraph) found in English, as well as other languages, contain two roots but form only a single PW. Indeed, the stress rules of English treat such items as single PWs, predictably assigning stress to different syllables throughout the word depending on the presence of certain suffixes (e.g., psychólogy/psychológical; télegraph/telegráphic). The status of such items is, however, controversial and detailed analysis is beyond the scope of the present paper.

It was suggested at the Conference that blends such as brunch or motel contain two roots. While this may be true of the nature of the coinage, there is no evidence that speakers view the words in question as anything other than simple lexical items such as lunch and hotel. 
well-formed syllables, a requirement for PW status. For example, in baab beet 'house door', the roots $\{\mathrm{bb}\}$ and $\{\mathrm{bt}\}$ may not form PWs on their own, but do so only with the addition of the requisite vowels. ${ }^{10}$

\subsection{Implication 3: Affixes do not constitute PWs}

In a number of analyses, it has been proposed that PWs may consist of a single affix. For example, Wiese (1996) argues that the diminutive suffix -chen in German constitutes a PW, as in (13), and similar arguments have been adduced for other languages (e.g., Booij 1985, for Dutch). The asterisk in this example indicates that the structure is in violation of the Generic PW definition provided above.

(13) German: PW $=*$ affix

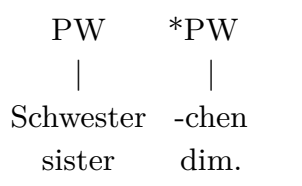

A typical argument for such an analysis is the fact that the suffix can be "factored out", as shown in (14) (cf. Wiese 1996).

(14) German: factoring out

Bruder-chen oder Schwester-chen $\rightarrow$ Bruder- oder Schwester-chen brother-dim or sister-dim

'little brother or little sister'

It is true that not all affixes in German exhibit this type of behavior, however, claiming that the affixes that do exhibit the behavior are PWs has undesirable consequences for the definition of the PW. That is, we are no longer able to maintain a single set of defining phonological properties. Specifically, one of the characteristic properties of the PW in German is that there must be at least one full vowel; however, -chen does not have a full vowel. If we argue that -chen is a $\mathrm{PW}$, we are no longer able to maintain the PW as the domain of this phonotactic/minimality constraint. Thus, considering the suffix as a PW constitutes a violation of

10 Booij (1999) argues on the basis of stress that certain morphologically simple words of Dutch nevertheless contain more than one PW (e.g., aalmoes 'alms', p. 59). 
the Generic PW definition above, as well as the generally accepted view of the PW as the domain for certain phonological rules and constraints in a language.

\subsection{Implication 4: Clitics and other function words do not constitute PWs with roots}

It was originally proposed that clitics, like the affixes just mentioned, formed separate PWs in accordance with the Strict Layer Hypothesis (SLH) (e.g., Nespor-Vogel 1986). In subsequent analyses, however, the SLH was somewhat relaxed (cf. among others Itô-Mester 1992; Vogel 1999) with the consequence that it was no longer necessary to consider clitics PWs. This is a desirable result since clitics typically do not exhibit the phonological properties of PWs such as stress assignment, minimality, and certain phonotactic constraints. An alternative analysis of clitics as forming part of PWs with the associated roots, however, yields other undesirable results. In fact, this possibility is excluded under the present proposal for the Generic PW definition.

In a detailed analysis of Italian, Peperkamp (1997) argues that clitics must not be considered independent PWs but rather must be subsumed under the PW of the relevant root, or host. Furthermore, it is argued that the way in which clitics are grouped with the host into the PW may vary across dialects. For example, in the Lucanian dialect, clitics are subsumed directly under the PW with the host, while in the Neapolitan dialect, they are subsumed as sisters to the PW under another, higher level, PW, as shown in (15a) and (15b), respectively (op.cit., 177). The asterisks again indicate that the structures would be excluded by the Generic PW definition proposed above.
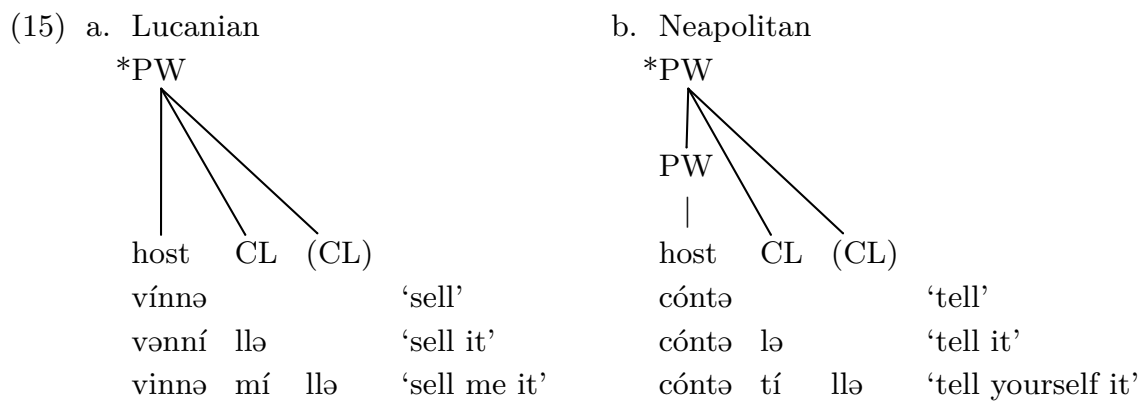
These structures are proposed on the grounds that stress assignment involving clitics exhibits different patterns in Lucanian and Neapolitan. In the former, stress always shifts to the penultimate syllable of an encliticized string, regardless of the number of syllables. By contrast, in the latter, a single clitic does not affect the stress pattern, however, if two clitics are present, an additional stress appears on the first one (ibid., 177).

The problem with such analyses is that they obscure the fact that there are, in fact, distinct stress patterns for the PW containing the root and associated suffixes (i.e., the host) and those for the strings including the clitics. In both dialects, as well as in standard Italian, stress appears on one of the final three syllables of the (phonological) word. It is not always penultimate as in the case of the Lucanian structures with clitics or in the case of Neapolitan structures with two clitics. Furthermore, stress is not regularly found more than three syllables from the end of the word as it is in Neapolitan when a single affix is added to verb forms with antepenultimate stress (e.g., péttinalə 'comb them') (ibid., 180). ${ }^{11}$

If the $\mathrm{PW}$, as a phonological constituent, is identified as a string that exhibits a set of crucial defining phonological properties, we cannot consider both the root and suffixes to be a PW and the combination of this PW and clitics also to be a PW. That is, if there are distinct properties, such as stress assignment rules, associated with the different types of strings, it follows that these strings must not be instances of the same phonological constituent. In fact, analyses such as Peperkamp's need to distinguish between phenomena that apply to the "inner" or "lower" PW and those that apply to a larger or "higher" PW. Instead of overtly labeling the constituents such that the different phonological phenomena can be assigned to the appropriate domain, such an approach makes it necessary to assign the phenomena to different strings based on additional descriptions of the strings.

${ }^{11}$ In standard Italian there are actually two verb forms in which stress appears on the pre-antepenultimate syllable of a small set of verbs, the third person plural of the present indicative and present subjunctive (e.g., péttinano 'they comb', péttinino 'that they comb'). It should be noted, however, that such forms are quite rare, and they have nothing to do with the presence or absence of clitics. 


\subsection{Implication 5: PWs and excluded items form a distinct higher constituent}

As has been argued above, the PW is strictly defined, such that clitics as well as affixes that do not participate in the phonological phenomena that are crucially associated with that domain are excluded from the PW constituent. These items are then adjoined as sisters of the PW into the next higher prosodic constituent. The result is schematically represented below. ${ }^{12}$

(16) PW and excluded items

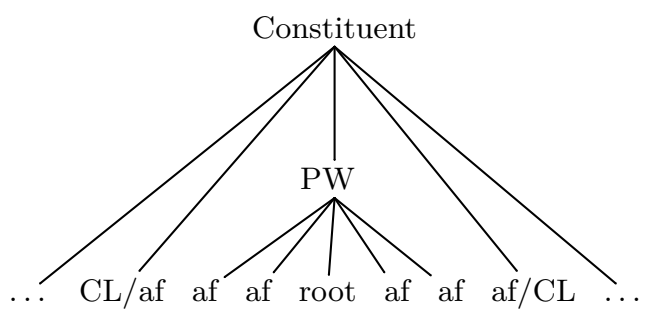

In Nespor-Vogel (1986), as well as a number of other analyses (e.g., Hayes 1989; Vogel 1999; Kabak-Vogel 2001), the constituent directly above the PW is the Clitic Group (CG). In this model, the PW and any excluded items are first grouped into the CG, and then CGs are grouped into the still higher constituent, the Phonological Phrase (PPh), as shown in (17).

(17) Phonological hierarchy with Clitic Group

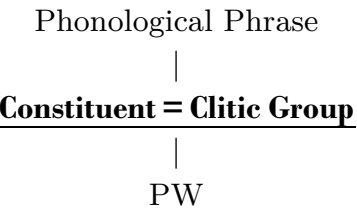

As mentioned above, the CG has come under attack as a constituent in a number of cases (cf., among others, Booij 1996; Peperkamp 1997). A common objection appears to be the fact that the CG could not appropriately be defined as consisting uniquely of the directly lower constituents,

${ }^{12}$ In the impressive array of languages analyzed in Dixon-Aikhenvald (2002), affixes, clitics and certain function words are included in a recursive type of PW with the host. Although it is beyond the scope of the present paper to reanalyze the data from these languages, it appears that they, too, may be more appropriately analyzed as containing a PW and also a larger CG constituent. 
PWs, as this would require that clitics and certain affixes be considered PWs on their own. Furthermore, in such a model, the CG was very frequently co-extensive with the PW it dominated. Once the SLH is relaxed somewhat, such objections are no longer pertinent. The alternatives that have been proposed in which additional types of PW are posited turn out simply to be a means of delimiting new phonological domains without assigning them distinct node labels, as in the case of the Italian dialects discussed above.

It should be noted that a different type of objection to the CG might also be raised. That is, at least in some cases, it appears that a constituent between the $\mathrm{PW}$ and the $\mathrm{PPh}$ is needed to group the elements of a compound into a single phonological constituent. This can be seen, for example, in the fact that in English one type of stress rule applies within the PW, while another type applies to compounds and yet another to phrases (cf. White House vs. white hóuse). While White House clearly contains two PWs, it is not possible to simply join them into a PPh, since this would incorrectly predict that they should exhibit the same stress pattern as the phrase white hóuse. Since there already exists a constituent between the PW and the PPh - the CG - it has been proposed that this is, in fact, the domain that accounts for the compound structures in question (cf. Vogel-Raimy 2002; also Kabak-Vogel 2001 for a similar analysis of Turkish). That is, the facts are accounted for on the basis of the CG, and there is no need to introduce an additional constituent between the $\mathrm{PW}$ and the PPh. The potential problem with this is a terminological one. While the term Clitic Group is quite appropriate for structures involving clitics, and even certain affixes, it does not accurately represent structures consisting of compounds. An alternative term-Composite Group - may be adopted instead, as this more appropriately reflects the varied elements that may be included within this constituent.

Returning to the case of Italian dialects, under the analysis proposed here, the structures of the Lucanian and Neapolitan examples seen in (15) would both be the same, as in (18). Indeed, the same structure would also be posited for the corresponding items in standard Italian.

In this way, it is possible to maintain the generalization about stress assignment being limited to one of the last three syllables of the PW in the dialects in question, as well as in standard Italian. Instead of three different constituent structures for Italian and the two dialects, the three varieties are united in sharing a common prosodic constituent structure. The difference is then expressed in the nature of the stress assignment 
(18) a. Lucanian

$\mathrm{CG}$

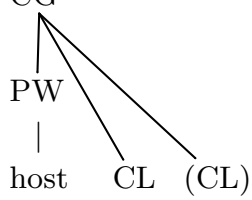

vínnə 'sell'

vənní llə 'sell it'

vinnə mí llə 'sell me it' b. Neapolitan

$\mathrm{CG}$

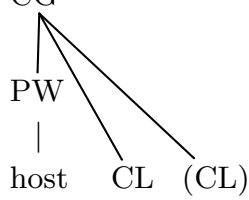

cóntə 'tell'

cóntə lə 'tell it'

cóntə tí llə 'tell yourself it'

phenomena at the level of the $\mathrm{CG}$, which is appropriate since what is at issue here is precisely the different way in which stress is assigned in the presence of clitics in each of the varieties of Italian.

Thus, it can be seen that it is not necessary to include clitics within the PW, and furthermore, that doing so tends to result in the introduction of additional domains although they are not identified as such. Instead, the Generic PW definition that excludes clitics and certain affixes from that domain permits them to be grouped directly into the next higher constituent in the prosodic hierarchy, the CG, along with the associated PW.

\section{Testing the generic $P W$ - polysynthetic languages}

If the PW is to be considered a basic component of the phonological hierarchy, the prediction is that it should be observed cross-linguistically, and it should have analogous phonological functions and properties regardless of the morpho-syntactic structure of a given language. Indeed, it has been shown thus far that a very simple definition of the PW, the Generic PW definition provided in (9) above, accounts for phonological structures and the related phonological properties in languages with a variety of different morphological properties, including isolating, fusional, agglutinating and templatic languages. The question addressed now is whether the same Generic PW definition also applies to, and provides an insightful analysis of, languages that are considered to have rather different, and more complex morphological structures, the so-called polysynthetic languages. For this purpose, the Algonquian language Cree is examined. The data discussed below are based on Russell's (1999) analysis of the Plains and Swampy dialects of Cree. 


\subsection{Cree verbal complex}

According to Russell (1999), the verbal complex of Cree consists of several positions before the stem, and up to ten suffixes following it, arranged in a template as in (19). An illustration of this structure is given in (20).

(19) Cree verbal complex (Russell 1999, 204)

Person Prefix (Preverb/s) Stem Suffixes

(Positions 1-10)

(20) Cree example

$\begin{array}{lll}\text { [nikî-maci-pamihikonânak] 'they looked after us badly' } \\ \text { ni } & \text { prefix } & \text { pe1 } \\ \text { kî } & \text { preverb } & \text { past } \\ \text { maci } & \text { preverb } & \text { 'badly' } \\ \text { pamih } & \text { stem } & \text { 'care for' } \\ \text { ko } & 2 & \text { inverse theme sign } \\ \text { nân } & 5 & 1 \text { pl exclusive } \\ \text { a } & 8 & \text { pe3 } \\ \text { k } & 9 & 3 p l\end{array}$

As can be seen, not all positions are filled in any given verbal complex.

\subsection{Phonological properties of the Cree verbal complex}

Russell argues that Cree, like other languages, crucially makes use of the $\mathrm{PW}$ in delimiting the domain of certain phonological phenomena. Specifically, the PW serves as the domain for primary stress, as well as for several other phonological rules such as Final Devoicing and sandhi phenomena. While the entire verbal complex has been analyzed as a single morpho-syntactic word, it should be noted that the preverbs do not participate in the stress pattern observed in the sequence of the stem and (certain) suffixes, and may actually exhibit their own stress patterns. Furthermore, the phonological rules observed in the same sequence of stem plus suffixes tend to be interrupted at the edges of the preverbal elements. This is not to say, however, that all suffixes combine with the root into a single PW. Rather, Russell points out that the phonological rules in question only apply in strings including the stem and any suffixes up to position 5 in the template. On these grounds, Russell argues that strings that have traditionally been identified as morpho-syntactic 
words, in particular verbal complexes, do not actually constitute single constituents from the perspective of phonology, but rather may contain several PWs.

\subsection{Cree phonological structure}

Given the distribution of stress and the application of several phonological rules, Russell proposes that Cree "words" are actually Phonological Phrases, which may comprise a number of smaller Phonological Words, as shown in (21). ${ }^{13}$

(21) Phonological structure of verbal complex (Russell 1999, 213)

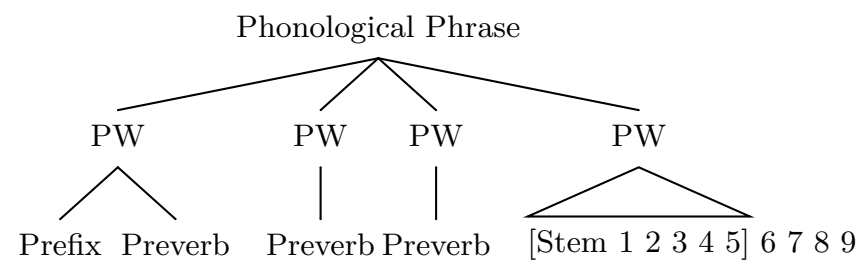

This structure reflects the observations that the Preverbs seem to constitute their own phonological domains analogous to the domain with the stem and (certain) suffixes. It also captures the fact that the crucial PW properties apply with the stem and suffixes only to position 5 in the template. It should be noted, however, that no account is given for any suffixes that are excluded from the PW.

While Russell's proposed phonological structure for Cree is similar in some respects to the PW structures proposed here for other types of languages, there are several differences. Most notably, as mentioned, the suffixes excluded from the PW with the stem are left unattached to any phonological constituent. It is not clear how they would be subsumed into the full phonological hierarchy of the language. The proposal advanced here, however, would automatically subsume such excluded items in the next higher constituent with the PW, the Clitic Group, as in (22). Thus, Cree can be seen to behave similarly to more familiar types of languages discussed above, in that the suffixes that do not participate in stress and other phonological rules with the stem (and closely associated suffixes),

${ }^{13}$ Rice (1993) proposes an analysis along similar lines for Slave, an Athabaskan language. 
are adjoined as sisters to the PW with the stem, without first forming higher constituents such as PWs on their own.

(22) Phonological structure of verbal complex - revised

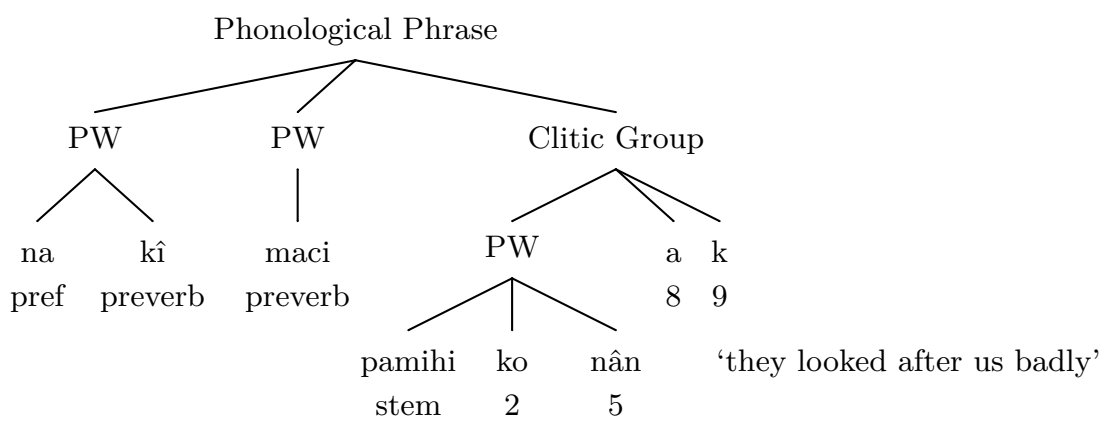

It should be noted that at least the first preverbal element that Russell considers to constitute a PW does not seem to contain what could be considered a root. Thus, it appears to violate Implication 1 which requires that the smallest PW be at least a root. It might turn out, however, that the items in this PW are actually part of a CG with the next PW, which would appear to contain a root, maci, translated as 'badly'. More detailed information about the phonological rules that apply or fail to apply in these constructions would be needed in order to definitively determine their constituent structure.

Regardless of the status of the first PW above, the primary conclusion is that the PW in Cree is fundamentally comparable to that in other types of languages. That is, despite the more complex (grammatical) word structure of this polysynthetic language, the proposed PW structure is simple and the strings it encompasses are not particularly long. In fact, this result is consistent with Russell's observation that the view of extremely complex word structures in polysynthetic languages may not actually be correct. Instead, he suggests that "'words' (whether syntactic, morphological, or phonological) are generally a great deal smaller than the literature on North American languages has traditionally suggested" (op.cit., 203).

\section{Conclusions}

It has been shown that while Grammatical Words may range from very short in isolating languages to very long in polysynthetic languages, we 
do not find comparable diversity among the corresponding Phonological Words. While we find small (single-morpheme) PWs across various types of languages, not only in isolating languages, we do not find extremely long PWs, even in polysynthetic languages.

The Generic PW definition proposed above results in the construction of simple and quite similar PWs cross-linguistically. The PWs thus constructed are strikingly similar despite substantial typological diversity at the morpho-syntactic level. As a result, the view that the PW roughly corresponds to the GW in a given language turns out to be accurate only for certain languages, for example, many isolating languages with quite simple GW structure. In other cases, however, relatively complex GW structure is not matched by similarly complex PWs. Instead, the PWs in these languages, too, are constructed in the same simple and straightforward way as in languages with less complex GW structure. In fact, this is precisely the result predicted by the general principles of prosodic phonology, according to which phonological structures are mapped from morpho-syntactic structures, but are not necessarily isomorphic to them. In this way, various types of morphological and syntactic constructions yield relatively simple, and cross-linguistically quite similar, phonological constituent structures. The Phonological Word is thus no exception to this generalization.

\section{References}

Beck, David 1999. Words and prosodic phrasing in Lushootseed narrative. In: HallKleinhenz (1999, 23-46).

Booij, Geert 1983. Principles and parameters in prosodic phonology. In: Linguistics $21: 249-80$.

Booij, Geert 1985. Coordination reduction in complex words: A case for prosodic phonology. In: Harry van der Hulst - Norval Smith (eds): Advances in nonlinear phonology, 143-60. Foris, Dordrecht.

Booij, Geert 1996. Cliticization as prosodic integration: The case of Dutch. In: The Linguistic Review $13: 219-42$.

Booij, Geert 1999. The role of the prosodic word in phonotactic generalizations. In: Hall-Kleinhenz (1999, 47-72).

Comrie, Bernard 1981. Language universals and linguistic typology. The University of Chicago Press, Chicago.

Czaykowska-Higgins, Ewa 1998. The morphological and phonological constituent structure of words in Moses-Columbia Salish (Nxa'amxcín). In: Ewa CzaykowskaHiggins - M. Dale Kinkade (eds): Salish languages and linguistics: Theoretical and descriptive perspectives, 153-95. Mouton de Gruyter, Berlin \& New York. 
Dixon, Robert Malcolm Ward 1980. The languages of Australia. Cambridge University Press, Cambridge.

Dixon, Robert Malcolm Ward-Alexandra Y. Aikhenvald (eds) 2002. Word. Cambridge University Press, Cambridge.

Downing, Laura 1999. Prosodic stem $\neq$ prosodic word in Bantu. In: Hall-Kleinhenz (1999, 73-98).

Hall, Tracy A. 1999a. German function words. In: Hall-Kleinhenz (1999, 99-131).

Hall, Tracy A. 1999b. The phonological word: A review. In: Hall-Kleinhenz (1999, 122).

Hall, Tracy A.- Ursula Kleinhenz (eds) 1999. Studies on the phonological word. John Benjamins, Amsterdam \& Philadelphia.

Hayes, Bruce 1989. The prosodic hierarchy in meter. In: Paul Kiparsky-Gilbert Youmans (eds): Rhythm and meter, 201-60. Academic Press, New York.

Itô, Junko-Armin Mester 1992. Weak layering and word binarity. Linguistics Research Center, Santa Cruz.

Kabak, Baris - Irene Vogel 2001. Stress in Turkish. In: Phonology 18:315-60.

Mitchell, T. F. 1962. Colloquial Arabic: A complete course for beginners. Harder and Stoughon, Kent.

Nespor, Marina-Irene Vogel 1982. Prosodic domains of external sandhi rules. In: Harry van der Hulst-Norval Smith (eds): The structure of phonological representations. Part I, 225-55. Foris, Dordrecht.

Nespor, Marina - Irene Vogel 1986. Prosodic phonology. Foris, Dordrecht.

Peperkamp, Sharon 1997. Prosodic words (HIL Dissertations 34). Holland Academic Graphics, The Hague.

Rice, Keren 1993. The structure of the Slave (Northern Athabaskan) verb. In: Sharon Hargus-Ellen Kaisse (eds): Studies in lexical phonology, 145-71. Academic Press, San Diego.

Russell, Kevin 1999. The "word" in two polysynthetic languages. In: Hall-Kleinhenz $(1999,204-21)$.

Selkirk, Elizabeth 1972. The phrase phonology of English and French. Doctoral dissertation, MIT.

Selkirk, Elizabeth 1980. Prosodic domains in phonology: Sanskrit revisited. In: Mark Aronoff-Mary-Louise Kean (eds): Juncture, 107-29. Anma Libri, Saratoga CA.

Selkirk, Elizabeth 1986. On derived domains in sentence phonology. In: Phonology Yearbook $3: 371-405$.

Vogel, Irene 1999. Subminimal constituents in Prosodic Phonology. In: Stephen J. Hannahs - Michael Davenport (eds): Phonological structure, 249-67. Foris, Dordrecht.

Vogel, Irene 2006. Phonological words. In: Keith Brown (ed.): Encyclopedia of language and linguistics (2nd edition), 531-34. Elsevier, Oxford.

Vogel, Irene- Eric Raimy 2002. The acquisition of compound vs. phrasal stress: The role of prosodic constituents. In: Journal of Child Language 29:225-50.

Wiese, Richard 1996. The phonology of German. Oxford University Press, Oxford. 